\title{
"SINGULARIDADES LITERÁRIAS" E "MACHADO DE ASSIS E A CRISE DE 93"
}

\section{R. MAGALHÃES JÚNIOR}

\author{
APRESENTAÇÃO DE MARTA DE SENNA \\ Fundação Casa de Rui Barbosa/CNPq \\ Rio de Janeiro, Rio de Janeiro, Brasil
}

Resumo: Em cada um dos dois artigos aqui apresentados, Raimundo Magalhães Júnior destaca e comenta uma crônica de Machado de Assis, publicadas ambas em novembro de 1893 em "A Semana", na Gazeta de Notícias. O propósito do crítico é chamar a atenção para a necessidade de que tais crônicas recebam, de estudiosos, a merecida interpretação e notas esclarecedoras sobre as particularidades de seu contexto. De fato, fincadas no tempo conturbado de Floriano Peixoto, de guerra civil, estado de sítio e boatos, essas crônicas, em que sobressai a arte de Machado de Assis de compreender a história e driblar controles exercidos sobre a imprensa, demandam um olhar crítico à altura do escritor.

Palavras-chave: a arte da crônica; "A Semana"; 1893; imprensa controlada; Floriano Peixoto

\section{"LITERARY SINGULARITIES" AND "MACHADO DE ASSIS AND THE CRISIS OF 93"}

\begin{abstract}
In each of the two articles presented here, Raimundo Magalhães Júnior emphasizes and discusses a chronicle by Machado de Assis, which were both published in November 1893 in the column, "A Semana," carried by Gazeta de Notícias. The critic aims to draw attention to these chronicles so that scholars provide them with the due interpretation and explanatory annotations regarding the particularities of the writings' context. In fact, stuck in the turbulent times of Floriano Peixoto, civil war, a state of siege and rumors, these chronicles, where the art of Machado de Assis excels at capturing history and dribbling around the restrictions placed on the press, require a critical look worthy of their writer.
\end{abstract}

Keywords: the art of the chronicle; "A Semana"; 1893; the restricted press; Floriano Peixoto 
Um rápido exame da bibliografia de R. Magalhães Júnior será suficiente para constatar a sua dedicação a Machado de Assis, de quem foi biógrafo minucioso, sobre cuja obra escreveu extensamente, além de ter sido, também, editor de seus contos "perdidos".

A biografia de Machado, em quatro volumes (Vida e obra de Machado de Assis), embora tenha passagens controversas, representa um esforço monumental de pesquisa e, embora nela se possam apontar falhas e lacunas, tem sido a inspiração de todas as posteriores. Até hoje é fonte incontornável de consulta sobre a vida do escritor.

Até meados da década de 1950, o leitor machadiano não especializado conhecia do autor pouco mais de setenta contos, aqueles que ele publicou em vida, em coletâneas sucessivas, ao longo de sua carreira de homem de letras: Contos fluminenses (1869), Histórias da meia-noite (1873), Papéis avulsos (1882), Histórias sem data (1884), Várias histórias (1896), Páginas recolhidas (1899) e Relíquias de casa velha (1906) - os dois últimos contendo não apenas contos, mas escritos diversos, como o famoso soneto "A Carolina", estampado na abertura da última coletânea.

Foi por volta de 1956 que R. Magalhães Júnior tomou a si a tarefa de publicar em livro (pela editora Civilização Brasileira) os contos que Machado votara à efemeridade dos periódicos, peças produzidas desde o fim dos anos de 1860 até o início do século XX. São cinco os volumes desses contos, a que o estudioso foi dando títulos mais ou menos sinônimos: Contos avulsos, Contos esparsos, Contos sem data, Contos recolhidos e Contos esquecidos. Estas publicações multiplicaram por três o número de contos machadianos acessíveis ao grande público, hoje todos disponíveis em edições eletrônicas, inclusive com notas em hipertexto (www.machadodeassis.net).

Quanto aos ensaios críticos sobre Machado de Assis, Magalhães Júnior os publicou na imprensa (sobretudo no Diário de Notícias, do Rio de Janeiro, de onde se retiraram os dois pequenos artigos que aqui se publicam) e também em livros, ainda hoje indispensáveis ao mais amplo conhecimento da obra do nosso ficcionista: Machado de Assis desconhecido (1955); Ideias e imagens de Machado de Assis (1956); Machado de Assis, funcionário público (1958); Ao redor de Machado de Assis (1958).

Os textos que aqui se publicam, com a autorização de Rosa Magalhães, filha do escritor, a quem os editores registram o seu agradecimento, saíram em dias sucessivos (29 e 30 de novembro de 1955) no Diário de Notícias, embora escritos, de acordo com uma afirmação no segundo deles, cerca de duas semanas antes. O grande interesse destes artigos, que se detêm sobre 
crônicas de "A Semana" (Gazeta de Notícias, década de 1890), é a luz que Magalhães Júnior (ele mesmo vítima do arbítrio durante o Estado Novo) projeta sobre a atitude irônica e corrosiva com que Machado de Assis denuncia a "ditadura" florianista, sem dizer uma só palavra sobre o momento que o país atravessava, a indicar, também na crônica, a capacidade de dissimulação do narrador machadiano.

\section{SINGULARIDADES LITERÁRIAS}

Texto publicado no Diário de Notícias, em 29 de novembro de 1955

\section{R. MAGALHÃES JÚNIOR}

$\mathrm{P}$ arte da obra de Machado de Assis já divulgada em volume está a merecer dos estudiosos um esforço de interpretação maior do que o que já foi feito e notas esclarecedoras de certas particularidades. Quando escrevia ele as crônicas de "A Semana" na velha Gazeta de Notícias, então órgão de excepcional prestígio, era já com grande sacrifício que o fazia. Menos pela idade, é certo, que pela saúde precária. Em 1893, desculpando-se pela brevidade de uma das crônicas, dizia: "Adeus. Curta é a crônica. Se soubessem como e de onde escrevo, com que alma turva, com que mãos cansadas, e com que olhos doentes!". Num homem discreto como era Machado essas frases parecem gemidos em público. Escrevia do leito de enfermo, talvez. As mãos cansadas eram as de um homem de cinquenta e quatro anos, com quase quarenta de vida literária. Os olhos de míope, que já quase perdera, a escorrer água, vermelhos, inflamados. E a alma turva? Aludiria vagamente à epilepsia, que o visitava frequentemente? Ou aos acontecimentos que então se desenrolavam no palco da nossa política, ou no cenário militar, onde já se definiam nitidamente as rivalidades entre o Exército e a Marinha, que fariam estalar uma das piores guerras civis do Brasil? Doente, chega Machado a faltar à sua coluna por uma semana. Ao reaparecer, alude de novo aos seus incômodos, citando os olhos. Fala no boato, no bombardeio, para dizer que não é isso, é apenas um coração que bate, e descreve o passeio de uma borboleta perdida na rua da Assembleia. Direis que Machado tinha, talvez, falta de assunto. Mas é que no momento em que ele via a borboleta perdida na rua da Assembleia as coisas não 
estavam lá para que digamos. Admira até que não tivesse visto bichos maiores. Olavo Bilac entrara numa "cana" dura, por ser antiflorianista e achar que o bravo marechal tinha usurpado o poder. Era assim que pensava Rui Barbosa - que acabou indo para a Argentina, com todas as suas imunidades. José do Patrocínio, que mantinha $A$ Cidade do Rio, fora desterrado para Cucuí. Solto, Bilac foge para Minas Gerais, onde também se asilam Carlos de Laet e Magalhães de Azeredo. Guimarães Passos também foge e vai para a Argentina. O estado de sítio decretado, e Floriano estava ameaçado pelos canhões da esquadra sublevada. A cidade estava cheia de boatos. Machado de Assis tinha uma coluna para encher em fase de imprensa controlada. Nesses períodos, não se diz o que não se quer. Quando muito, deixa-se de dizer o que se não quer.

Escreve então Machado de Assis uma de suas crônicas mais curiosas. Está, do princípio ao fim, cheia de notícias sensacionais, como resposta à pergunta, que todos fazem: "Que há de novo?". Mas as notícias são todas de cem, cento e cinquenta e duzentos anos de idade. "Uma calamidade, senhor! A cidade inteira em ruínas." Era a cidade de Lisboa, abalada pelo famoso terremoto, não a do Rio bombardeada. "A indignação pública vingara a morte de um traído", num "pupilo". Mas não era a de Deodoro vingada em Floriano. Era a punição do traidor Lázaro de Melo, no Maranhão, há duzentos anos. Vinha, depois, uma notícia de naufrágio. Algum navio rebelde metido a pique? Não: o naufrágio do navio em que viajava Gonçalves Dias... No final da crônica, diz Machado:

No sábado, notei que os perguntadores fugiam de mim, com receio, talvez, de ouvir a queda do império romano ou a conquista do Peru. Eu, por não fiar dos tempos, saí com a morte de Torres Homem no bolso: era recentíssima, podia enganar o estômago. Creio, porém, que a invasão da véspera bastou às curiosidades vadias. Não me arguam de impiedade. Se é certo, como já se disse, que os mortos governam os vivos, não é muito que os vivos se defendam com os mortos. Dá-se assim uma confederação tácita para a boa marcha das coisas humanas. Hoje não saio de casa; ninguém me perguntará nada. Não me perguntes tu também, leitor indiscreto, para que eu te não responda como na comédia, após o desenlace: "- Que há de novo?", inquire o curioso, entrando. E um dos rapazes: "Que vamos almoçar".

Não deixa de ser interessante a solução machadiana. Quando não se pode falar do presente com toda a liberdade e as garantias constitucionais, 
realmente o melhor é visar um passaporte para o passado, que é liberal por excelência, admitindo todos os juízos e todas as controvérsias.

\section{$* * * *$ \\ MACHADO DE ASSIS E A CRISE DE 93}

Texto publicado no Diário de Notícias em 30 de novembro de 1955

\section{R. MAGALHÃES JÚNIOR}

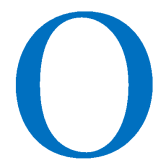
ntem, falando de Machado de Assis, aludimos aos tropeços de um cronista durante um período em que as garantias constitucionais se acham suspensas, não se pode ir e vir sem ser por mercê de alguém que pode em nome da ordem pública regular os nossos passos, nem dar ao nosso pensamento toda a latitude, porque, em dado momento, ele pode ser considerado subversivo, ainda que como tal não o tenhamos. Numa outra crônica, da mesma fase, continua o autor das Memórias póstumas de Brás Cubas a mexer no surrão das reminiscências históricas. Começa por dizer que, durante a semana, "os tiros comeram a maior parte do tempo" e fala da curiosidade despertada pelos bombardeios, que faziam a praia da Glória e a do Flamengo apinhada[s] de gente. "Uma vez", escreve Machado,

desci do bonde, na praia da Glória, para aceder ao convite de um amigo que queria ver o bombardeio. Desci ainda uma vez para escapar a um sujeito que me contava a guerra da Crimeia, onde não esteve, não havendo nunca saído daqui, mas que se ligava à sua adolescência, por serem contemporâneos. Ninguém ignora que os sucessos deste mundo, domésticos ou estranhos, uma vez que se liguem de algum modo aos nossos primeiros anos, ficam-nos perpetuados na memória.

Faço aqui uma pausa, para ligar uma referência desta crônica ao Dom Casmurro. Já o estaria escrevendo Machado em 1893? Voltou-lhe, depois, essa ideia da guerra da Crimeia? O fato é que ela é a base de um dos capítulos mais curiosos do livro, "A polêmica", travada entre Bentinho e Manduca, o pobre rapaz leproso que punha toda a ênfase de sua vida na afirmação de que "os russos não hão de entrar em Constantinopla!". Voltemos, porém, à crônica de 1893. O cronista pergunta: 
Por que é que, entre tantas coisas infantis e locais, nunca me esqueceu a notícia do golpe de Estado de Luís Napoleão? Pelo espanto com que a ouvi ler. As famosas palavras "Saí da legalidade para entrar no direito" ficaram-me na lembrança, posto não soubesse o que era direito nem legalidade. Mais tarde, tendo reconhecido que este mundo é uma infância perpétua, concluí que a proclamação de Napoleão III era como as histórias da minha meninice: "Entrou por uma porta, saiu por outra, manda El-rei nosso senhor que nos conte outra". Por exemplo: o dia de hoje, 12 de novembro, é o aniversário do golpe de Estado de Pedro I, que também saiu da legalidade para entrar no direito.

Podemos imaginar que outras associações de ideias desse gênero não teria sacado Machado de Assis, nesse período. Mas é escusado procurar novas crônicas do grande escritor no mês seguinte. Em dezembro, não decerto por causa das palavras dele, mas dos editoriais publicados, a Gazeta de Notícias teve a sua publicação suspensa por ordem do governo, conforme a nota dos editores que se lê ao pé da página n. 434, primeiro volume, da última edição de "A Semana" (W. M. Jackson, Inc.) Essa história de sair da legalidade para entrar no direito evidentemente não cheirava bem ao cronista. O golpe de Estado de Pedro I não chegara a constituir uma infringência da Constituição, porque esta, então, ainda não existia. Foi um golpe abortivo, pois que dissolveu a Constituinte que ia elaborá-la, prendendo os Andradas e outros brasileiros ilustres e desterrando-os para fora do país.

O golpe de Luís Napoleão foi uma traição à República Francesa, em benefício de um imperador de opereta. E Floriano? O erro começara em Deodoro, quando o golpe de Estado de 3 de novembro de 1891 dissolveu ilegalmente o Congresso, assumindo poderes ditatoriais. Forçado a renunciar, Floriano também se colocou, ao substituí-lo, fora da legalidade. Legalmente, teria de convocar eleições para a escolha de um novo presidente. Não o fez. E embora o Congresso tivesse funcionado durante todo o seu período de governo, nem por isso esse período deixou de ser uma ditadura, porque a sua posição no Poder não era legítima. Houve, é certo, pareceres artificiosos, que sustentavam a validade de sua permanência. Mas aqueles que, além de grandes constitucionalistas, haviam elaborado a própria Constituição, como Rui Barbosa, eram de parecer inteiramente oposto. Floriano Peixoto era, embora Machado de Assis no momento não pudesse escrevê-lo, mais um que tinha "saído da legalidade para entrar no direito"... 